\title{
Investors' Financing Risk Prediction in Crowd-funding Platform
}

\author{
Hongjian $\mathrm{Li}^{1, \mathrm{a}}$ and Yan Shao ${ }^{2, \mathrm{~b}^{*}}$ \\ ${ }^{1}$ Lanzhou University of Technology, China \\ ${ }^{2}$ Lanzhou University of Technology, China \\ a914435055@qq.com, b2436249761@qq.com
}

Keywords: Crowd-funding; Financing risk; Neural network model; Risk prediction

\begin{abstract}
Internet finance is a popular trend nowadays. The financing risk is an issue that can not be neglected. This paper uses the data of "Roll call time" crowd-funding platform to construct a forecast model of financing risk based on neural network to study the disclosure of personal information and expected return. The impact of the forecast on the financing risk: there is "cater" phenomenon in the disclosure of personal information, and the expected return of the project prospect has a positive impact on the forecast. This provides the basis for more comprehensive risk forecasting and sound credit rating evaluation.
\end{abstract}

\section{Introduction}

With the rapid development of the Internet, borrowers began to consider Internet finance when choosing financing methods. Crowd-funding platform through the mass force, to break the original bond financing for the financier for our country's financial market has brought vitality and competitiveness, increased liquidity of capital, social capital can be effectively used for both investment and financing to establish a mutually beneficial effective investment channels.

At the beginning of entrepreneurship, young entrepreneurs mainly originated from their own or small self-raised funds, but they did not have enough funds to meet the production needs of enterprises because crowd-funding platforms had a low threshold. The advantages of more and more entrepreneurs will favor crowd-funding platform to finance. However, most entrepreneurs are small and micro enterprises, with small enterprises, few assets that can be pledged, and inadequate financial systems. As a result, there will be information asymmetry among financiers, resulting in unsuccessful financing.

Nowadays, some documents have researched the risk identification of investors to borrowers from the perspective of peer-to-peer lending on the internet, but have not conducted research in the perspective of crowd-funding platform. In the study of P2P lending, Logit model is usually used to analyze the influencing factors of risk, but the neural network measurement model is not used to fit the actual situation of risk prediction. Therefore, the innovation of this paper lies in the use of neural network model to analyze the financing risk of crowd-funding platform crowd-funding factors to study the investors through which factors to determine and predict whether the project can finally be successful financing.

\section{Literature review and Research hypothesis}

As a new type of financial business model, Internet finance has been cooperating with Internet companies through modern information technologies such as the Internet and mobile communications to realize the functions of financing, payment and wealth management (Niu Qiang, $\mathrm{Hu} \mathrm{Yi}, 2015)[1]$. Mainly includes two forms: P2P network lending, crowd-funding platform. Its essence still belongs to the financial category, and there is no issue of avoiding default risk caused by asymmetric information. Therefore, credit risk management remains an important issue for crowd-funding platforms and even Internet finance. Financing As the first step in the whole process, financing risk is the beginning of information asymmetry. How investors judge and predict the success of the final financing is crucial. Financing risk is in the process of crowd-funding financing, due to the asymmetric information of financiers and investors, resulting in the risk of the ultimate 
crowd-funding unsuccessful.

Liao Li, Li Mengran and Wang Zhengwei(2014)[2] analyzed and verified that investors' investment decisions in the $\mathrm{P} 2 \mathrm{P}$ online lending market mainly depend on the content and quantity of information disclosed by the borrower on the Internet, the credit rating of the project manager, the age Hard information is not only closely related to the probability of full success (Lin, 2009; Pope and Sydnor, 2011)[3,4], and investors' investment decisions depend largely on the information disclosed by the borrower (Niu Qiang, Hu Yi, 2015)[1]. However, in Yue Zhonggang's (2016)[5] empirical analysis of $\mathrm{P} 2 \mathrm{P}$ online lending, it is found that the number of non-certified information disclosed by the lenders is negatively correlated with the credit risk but there is a "cater" factor that the fund-raisers may have in order to raise funds. Investors can be confused by choosing or even filling in false information, a "lemon concept" proposed by Felo (2013)[6]. The same is the platform for crowd-funding of Internet finance, is there a problem that information disclosure will "cater to" investors. So in the crowd-funding platform to look at the financing risk forecast to take into account such information noise, which made Hypothesis 1:

H1: Borrowers' disclosure in the crowd-funding platform "caters" investors, misleading the prediction of financing risk.

Crowd-funding platform "Roll call time", the amount of investment is different, the amount of the return will be changed, which are set by the financiers themselves. Fan Jiachen (2013)[7] argues that the logic of value of the crowd-funding business model lies in value discovery, value matching and value acquisition. Disclosure of information by financiers will allow investors to value the value of the project. In matching the value of the project, the investor will consider the amount of each aspect of the return and thus invest in the project in return. Zhao Yongxue (2013)[8] combined qualitative and quantitative research found that available financial compensation has a positive impact on the willingness to crowd-funding investment. Therefore, in the value matching process, the return amount reached the expectations of investors in mind, when investors look at the investment project will have a forecast and determine the return, which made Hypothesis 2:

$\mathrm{H} 2$ : A good expected return will increase the accuracy of the financing risk forecasting; the poor expected return will reduce the accuracy of the financing risk forecasting.

\section{Model Building}

Choice of Financing Risk Assessment Model. The assessment of financing risk will use the default risk assessment model, but on the basis of which, the model with the best model result will be selected for evaluation. Sunsen, Wang Ling (2014)[9] and Cao Ping (2015)[10] used KMV model to study the probability of firm's default risk. The model considers the credit risk of a loan to be determined by the debtor's asset market value in the case of a given debt. However, the assets do not really trade in the market, the market value of assets can not be directly observed, and the model is too harsh in the assumptions, the actual return on assets can not fully meet the normal distribution conditions, indicating that this model has some limitations, the risk prediction There can be no good judgment rate. Zhou Yong, Xie Shangyu and Yuan Yuan (2008)[11] think that the structural model has many problems. The most prominent one is that it is hard to estimate the short-term credit spread, and it is easy to underestimate the probability of default in the short-term deadline. At the same time, it is considered that the traditional minimalistic model will lead to the unpredictable probability problem due to the increased covariates. Chen Shoudong, Li Xiaochun, and Liu Bing (2009)[12] found that neural network model is the best one to measure the credit default risk by comparing with the credit risk default probability measurement models of factor score, multivariate discriminant, Bayesian discriminant, Logit regression and neural network make early warning judgments. Yu Liyong (2003)[13] considered neural network metro-logy model as a kind of non-parametric method with self-organizing, self-adaptive and self-learning characteristics. The distribution of sample data is not strict, not only has nonlinear mapping ability and generalization ability, but also At the same time, Chen Shoudong, Li Xiaochun, and Liu Bing (2009)[12] think that neural network econometric model fully takes into account the nonlinear relationship between the probability of default of credit risk and financial variables. To sum up, this article will select the 
neural network measurement model for the assessment and prediction of financing risks, to tap the sample more in line with the actual relationship.

Data source. Because the Roll call time is the earliest time China established, currently the largest return-based crowd-funding platform, but also refers to the United States largest crowd-funding platform Kickstarer platform model established, representative. In this study, we took the web crawling method to obtain the transaction records of the platform from 2014 to August 2017. In order to make the data more representative, we screened out: (1) deleted the project with the per-financing amount of less than 500 yuan Transaction records, because per-funding below 500 yuan is not strictly crowd-funding. (2) Within the scope of the transaction record, pick the successful financing transaction records, that is, the actual financing amount is greater than the target amount, and the financing failure of the transaction record in the actual fund-raising more than zero project, the actual fund-raising is greater than zero Less than the target amount. (3) deleted the sponsor is located in the non-mainland areas of the project. (4) deleted the data missing items. A total of 186 transaction records.

Variable selection. Through the public information of the time-sharing crowd-funding platform, nine specific indicators of two major items were selected as independent variables. Respectively, information disclosure and expected return. Specific indicators are: video, the number of pictures, the number of announcements, personal introduction, the target amount [RMB], the actual amount [RMB], the proportion of financing [percent], the return of stalls [species], the comprehensive score [points]. The dependent variable is judged by whether the financing is successful, that is the financing success $=1$ and the financing failure $=0$.

\section{Measurement Process of Neural Network Model}

BP neural network model is a one-way propagation multi-layer forward neural network model, using a gradient descent algorithm, iterative solution to a set of samples of the input and output into a nonlinear optimization problem. BP neural network consists of three layers: input layer, output layer, hidden layer. By constructing the neural network, the number of nodes is randomly initialized to a relatively small random number. The training samples are input to the output nodes to calculate the output of each layer. The errors are calculated and propagated backwards by updating the weights and the thresholds reflecting the network prediction errors. Find the error function to determine whether the error converges within a given precision, if convergence, learning is over; otherwise, continue to learn. As shown in Fig. 1, nine indicators are used as input neurons, and finally whether the financing is successful or not, [0,1] algebraic values are taken as output neurons. Adjusted in the hidden layer nodes at many times that 9 is more appropriate.

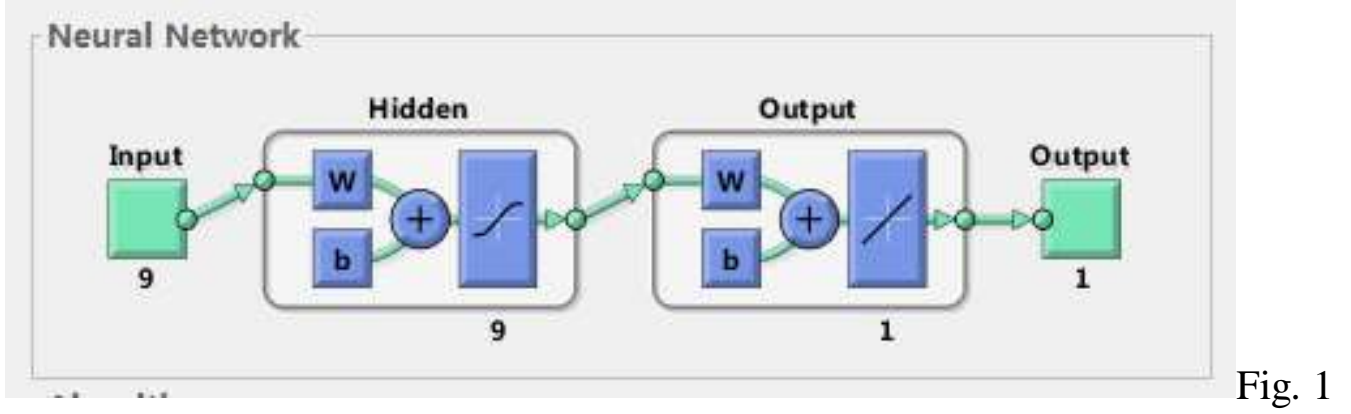

In MATLAB 2017, using the neural network toolkit, the default training sample accounts for $70 \%$ of the total sample, the validation sample accounts for $15 \%$ of the total sample, and the testing sample accounts for $15 \%$ of the total sample. Due to the large total sample size, the MSE will not be too small. It can be seen from Figure 2 that the Mean Squared Error (MSE) of the test samples in the three samples is relatively low, which can better illustrate that the error between the output value and the target value is small, indicating that crowd-funding These indicators on the platform of the eventual financing success or not to effectively judge. Similarly, the performance of Fig. 3 is also a network output error representation. 


\begin{tabular}{|c|c|c|c|}
\hline \multicolumn{4}{|l|}{ Results - } \\
\hline & Samples & G MSE & $ه \mathbf{R}$ \\
\hline (1) Training: & 130 & $5.62927 e-2$ & $7.76911 \mathrm{e}-1$ \\
\hline 10 Validation: & 28 & $9.68662 \mathrm{e}-2$ & $4.64697 \mathrm{e}-1$ \\
\hline (1) Testing: & 28 & $1.45900 \mathrm{e}-1$ & $6.56817 e-1$ \\
\hline \multicolumn{4}{|l|}{ Progress } \\
\hline Epoch: & \multirow[t]{2}{*}{0} & 18 iterations & \multirow[t]{2}{*}{1000} \\
\hline Time: & & 0:00:01 & \\
\hline Performance: & 1.55 & 0.0363 & 0.00 \\
\hline Gradient: & 3.17 & 0.0485 & $1.00 \mathrm{e}-07$ \\
\hline Mu: & 0.00100 & 0.000100 & \multirow{2}{*}{$\begin{array}{l}1.00 e+10 \\
6\end{array}$} \\
\hline Validation Checks: & 0 & 6 & \\
\hline
\end{tabular}

Fig. 2

Fig. 3

Fig. 4 and Fig. 5 show the relationship between the expected return and the final successful financing under the conditions of information disclosure. The correlation coefficients are 0.37 and 0.15 respectively, which are all greater than 0 , indicating that the information disclosure and expectation The impact of rewards on the final outcome is positive. All we can say is that the more information disclosed, the more positive the success of the final financing. The more detailed and predictable the information given by the expected return, the more likely it is to judge the success of the final financing.
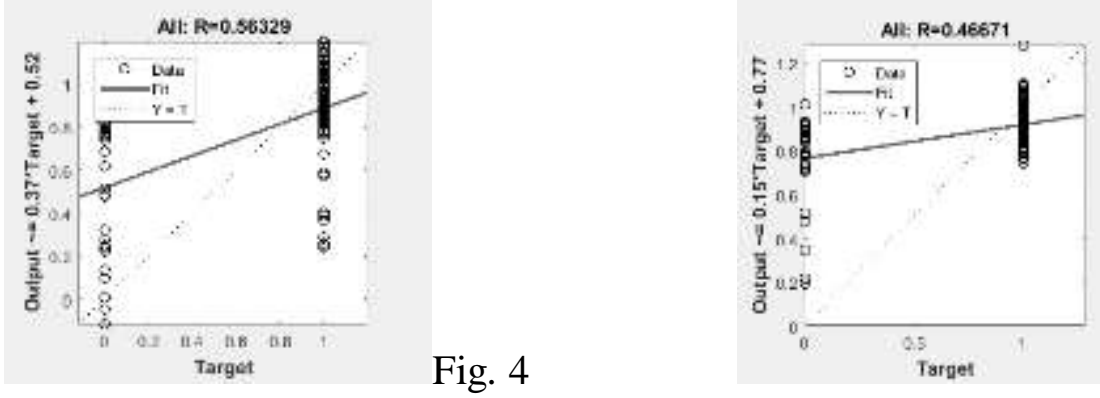

Fig. 5

Fig. 4 and Fig. 5 are the use of the traditional regression equation, the final result is the information disclosure and the expected return of the situation can have a positive impact on the final financing results. However, after the nonlinear optimization of the neural network model is used, the differences can be clearly seen in Fig. 6 and Fig. 7 . Fig. 6 shows that the training samples can not be optimally obtained by historical data under information disclosure. Through the change of the threshold in the neural network, Barely reach above the dotted line, that is, the best; This also confirms the hypothesis 1: the more the information disclosure, the possibility of the final financing is not very successful in the financing process there will be financing "cater" investors phenomenon .

However, both the training samples and the test samples of expected returns in Fig. 7 are much higher than the optimal requirements, indicating that the historical data can be analyzed to find the good state of expected returns can enhance the forecast accuracy of financing risks. The more detailed the expected returns, The possibility of the final financing risk will be lower. This also confirms the establishment of Hypothesis 2.

Fig. 8 is the result of neural network analysis of nine indicators. The results of Fig. 6 and Fig. 7 are more conclusively illustrated: when the investors invest, they pay more attention to the expected return than the financier's own detailed introduction. On the whole, Part of the results can be more effective look at the final financing, will better determine the risk of crowd-funding projects. 


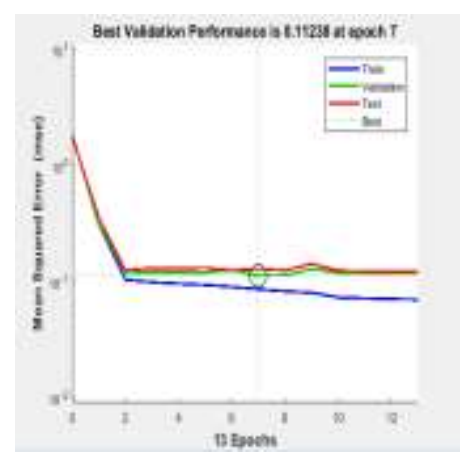

Fig. 6

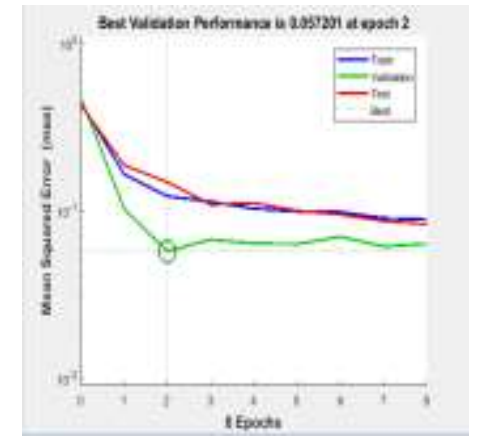

Fig. 7

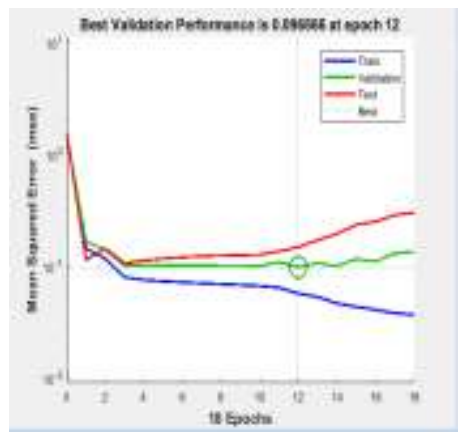

Fig. 8

\section{Conclusion}

In this paper, "Roll call time" data, for example, the use of Matlab 2017 established a linear regression equation and nonlinear neural network model, financing crowd-funding platform on the risk of data mining and comparison results, that the neural network model can mine the data deep Contact, there is more confidence in the risk prediction, fully validated the two hypotheses made.

Compared with linear results of regression equation, the nonlinearity of neural network model can dig out the inherent relationship of data, so as to discover the positive effect of "cater to" and expected return on information disclosure in crowd-funding platform. Therefore, during the investment process, investors can combine the information disclosed by the entrepreneur on the crowd-funding platform and the expected return from the development prospect of the project so as to comprehensively predict whether the project is worth the investment and judge the risk among them can better avoid losses, but also provide a basis for more comprehensive risk prediction and perfect credit rating evaluation.

\section{References}

[1] Q. Niu and Y. Hu: Yunnan Social Sciences, (2015)No.6,p.71.

[2] L. Liao, M.R. Li and Z.W. Wang: Economic Research, (2014)No.7,p.125.

[3] M. Lin, N.R. Prabhala and S. Viswanathan: Management Science, Vol. 59 (2013),p.17.

[4] D.G. Pope and J.R. Sydnor: Journal of Human Resources, Vol. 46 (2011),p.53.

[5] Z.G. Yue, Q. Zhou and X.J. Yang: Financial Finance, (2016)No.1,p.54.

[6] A.J. Felo: International Journal of Management Accounting Research, (2013)No.3,p.47.

[7] J.C. Fan: Management World, (2013)No.8,p.72.

[8] Y.X. Zhao. Analysis of Factors Influencing Crowd-funding Investors Participation Motivation(Master, University of International Business and Economics, China 2013),p.17.

[9] S. Sun, L. Wang: Accounting Monthly, (2014)No.9,p.64.

[10] P. Cao: Securities Market Herald, (2015)No.8,p.39.

[11] Y. Zhou, S.Y. Xie and Y. Yuan: Systems Engineering Theory and Practice, (2008)No.8,p.206.

[12] S.D. Chen, X.C. Li and B. Liu: Industrial Technology Economy, Vol. 28 (2009) No.4,p.139.

[13] L.Y. Yu: Journal of Management Sciences in China, Vol. 6(2009)No.5,p.46. 